\title{
Possible Factors Related to Phenotype Change from Adenocarcinoma to Squamous Cell Carcinoma
}

\author{
Takao Kinjo', Kazuya Kamiyama ${ }^{1}$, Katsuni Chinen', Akira Arasaki² and Teruo Iwamasa' \\ ${ }^{1}$ Division of Pathology and Cell Biology and ${ }^{2}$ Oral and Maxillofacial Functional Rehabilitation, Graduate School and Faculty of \\ Medicine, University of the Ryukyus, 207 Uehara, Nishihara, Okinawa 903-0215, Japan
}

Received May 21, 2003; accepted October 7, 2003

Squamous differentiation/squamous metaplasia is a common feature associated with lung and endometrial adenocarcinomas, but is very rare in the case of colonic and gastric adenocarcinomas. Cases of squamous cell carcinoma and adenosquamous carcinoma (criteria of the Japan Lung Cancer Society) of the lung and endometrial adenocarcinoma with squamous differentiation infected with human papillomavirus (HPV) are frequently seen in Okinawa. A correlation between squamous differentiation and HPV infection was demonstrated $(p<0.05)$ $[11,31]$, and the squamous cell carcinoma components are HPV-positive by in situ hybridization method. The adenocarcinoma cells adjacent to the squamous cell carcinoma components are enlarged, and are also positive for HPV. The production of high molecular weight keratin (HMK) (Moll's No. 1, 5, 10, and 14) $[1,14]$ and involucrin is induced in the squamous cell carcinoma component and also in adjacent enlarged cells. Further, in Okinawa, squamous metaplasia of the bronchial epithelium are occasionally positive for HPV by in situ hybridization. We postulated that HPV causes phenotype change/squamous metaplasia. We then transfected human papillomavirus 6,16 and 18 in plasmid pBR322 into cultured adenocarcinoma cells (DLD-1 [4] and PC-14 cells) [13, 16]. DLD1 cells were the cultured human intestinal adenocarcinoma (moderately differentiated), and PC-14 cells were cultured human lung adenocarcinoma. In our experiments, we chose these two cultured adenocarcinoma cells for following reasons. Squamous differentiation is fre- quently observed in the case of lung carcinomas, but rare in colonic carcinomas. We used one each of the cultured adenocarcinoma cell lines from both groups. Further, to investigate the effects of HPV transfection on apoptosis and inhibition of the growth, p53 gene mutated (inactivated) carcinoma cells [20, 34] were used. The phenotype change/squamous metaplasia was observed, and was apparent in the case of HPV 16 transfected DLD-1 cells, although in the case of human intestinal adenocarcinoma, squamous differentiation was very rare. It was considered that squamous differentiation was induced by HPV transfection regardless of the tissue type [13]. For this reason, in this report we consider HPV 16 transfected DLD-1 cells. Immunohistochemically HMK (Moll's No. 1, 5, 10 and 14) $[1,15]$ and involucrin [35] were strongly demonstrated in the cytoplasm of HPV transfected cells. Further, the transglutaminase $I$ [6] and involucrin mRNA were also detected by use of RTPCR. The growth of the HPV transfected cells was reduced, and the population of G0-G1 phase cells increased. The expression levels of the cell cycle related molecules, cdk2 and cyclin D3 decreased. On the other hand, the proportion of apoptotic cells increased, and the expression level of DNase $\gamma$ also increased markedly [13].

Although the HPV E6-p53 and E7-Rb interactions have been well known, transcriptional trans-activity of HPV for other cellular genes, for example, cytokeratin and cell cycle associated genes, might be considered $[13,33]$.

Key words: squamous metaplasia, phenotype change, human papillomavirus (HPV), DNA transfection 


\section{Introduction}

Phenotype change from adenocarcinoma to squamous cell carcinoma is observed in neoplasms, particularly in adenocarcinomas of the lung and uterus. The term "squamous differentiation" is generally used when a squamous cell carcinoma component is seen in the adenocarcinoma, and this is also considered as a change in phenotype. "Metaplasia" is the change in the differentiation pathway to which the stem cell progeny commit, and is the process whereby one type of differentiated cell is replaced by another, usually in response to abnormal stimuli [36]. "Metaplasia" is said to occur in tumors, but the term "metaplasia" is better used for change in non-neoplastic tissue [17]. The term "phenotype change" is appropriate in the case of tumors. The use of the terminology will be clarified by the recent progress in molecular research.

We previously reported that in human cases of adenosquamous carcinoma of the lung, the squamous cell carcinoma components were positive for human papillomavirus (HPV), as shown by in situ hybridization [11, 31, 32]. According to World Health Organization (WHO) criteria, adenosquamous carcinomas contain both squamous carcinomatous and adenocarcinomatous components. The proportions of each subtype required for diagnosis are not defined. However, according to the criteria of the Japan Lung Cancer Society, to qualify as an adenosquamous carcinoma a tumor should be composed of at least $20 \%$ each of the squamous cell carcinoma component and the adenocarcinoma component. In our present report we have employed the latter criteria. The adenocarcinoma cells adjacent to the squamous cell carcinoma components were enlarged, and also showed positive for HPV by in situ hybridization method. Production of high molecular weight keratin (HMK) (Moll's No. 1, 5, 10 and 14) [1, 15] and involucrin molecules [32] was induced in the squamous cell carcinoma components and also in the adjacent enlarged adenocarcinoma cells [31]. This was thought to indicate the transition from adenocarcinoma to squamous cell carcinoma. We postulated that when adenocarcinoma cells undergo morphologic changes (phenotype change), the expression of HMK and involucrin is caused by HPV infection [13, 16]. Although the importance of HPV infection to the development of squamous cell carcinoma, especially in uterine cervical carcinoma, has been well known, additional events are required for full malignant conversion, and attention has been focused on the E6/p53 and E7/Rb interaction $[5,18,30,33]$. However, in this report we did not describe the oncogenic function of HPV. Instead, we have focused our attention on the phenotype change induced by HPV genome from adenocarcinoma to squamous cell carcinoma.

Correspondence to: Takao Kinjo, M.D., Division of Pathology and Cell Biology, Graduate School and Faculty of Medicine, University of the Ryukyus, 207 Uehara, Nishihara, Okinawa 903-0215, Japan.

\section{Transfection and Transcription of HPV}

\section{Transfection of HPV and squamous differentiation}

We have examined many human cases of HPV infected adenosquamous carcinomas in the lung and endometrium in Okinawa [30], and observed the induction of involucrin and HMK molecules in the squamous cell components and also in the neighboring enlarged adenocarcinoma cells. Although our observation of the phenotype change was in tumor cells, Sun et al. [26] reported that cultured normal endocervical epithelial cells infected with HPV 16 formed an epithelium resembling squamous metaplasia. However, neither detailed examinations of HPV transcripts nor molecular biology was performed. In our experiment the combined expression of the E2 and E6-E7 fusion gene products was considered to be a factor for the phenotype change from adenocarcinoma to the squamous cell carcinoma [13]. However, it is well known that bovine papillomavirus (BPV) E2 proteins can repress E6 and E7 expression [12]. The overexpression of the BPV E2 decreased the transcription of HPV 16 from p97 promoter [5, 12], although under different conditions E2 protein activated the transcription of HPV from the same promoter. Sanchez-Perez et al. [21] and Bouvard et al. [2] have reported that the HPV E2 protein increased the E6 and E7 expression, and that the increase of E7 protein induced apoptosis $[23,24]$.

As reported previously $[13,16]$, transfection of HPV 6, 16 and 18 in plasmid pBR322 into two types of cultured adenocarcinoma cells (DLD-1 [4], a moderately differentiated colonic adenocarcinoma which had mutation of p53 gene at Ser241Phe (C936T) and PC-14, a poorly differentiated adenocarcinoma of the lung which also had p53 gene mutation at Arg248Trp (C956T)), was carried out using Chen and Okayama's calcium phosphate method [3]. Neomycin and hygromycin were used as selection markers. The HPV transfected cell clones are shown in Table $1 \mathrm{a}$ and $\mathrm{b}$. The phenotype change/squamous metaplasia was more apparent in the case of HPV 16 transfected DLD-1 cells, especially 16D1 (Table 1a), than in either HPV 6 and 18 transfected DLD-1 cells, or HPV 6, 16 and 18 transfected PC-14 cells. The HPV transfected cells showed the presence of integrated forms of the virus by analysis of the restriction endonuclease digestion. They became enlarged with abundant cytoplasm (Fig. 1), and were tightly adherent to the dishes. After the HPV transfected cells were injected into the backs of SCID mice, tumors formed. Histologically, the HPV tansfected DLD-1 cell (16D1) tumors were moderately differentiated squamous cell carcinoma showing abundant cytoplasm (Fig. 2a, b). However, in the case of HPV transfected PC-14 cells, basal cell differentiation was frequently observed, and prickle cells were less frequently found (Fig. 2c, d). It is thought that the poorly differentiated characteristics of PC-14 cells and the expression pattern of HPV mRNA might influence the differentiation of the metaplastic cells [13]. Immunohistochemically HMK and involucrin were strongly demonstrated in the cytoplasm of HPV transfected DLD-1 and PC-14 cells [13]. Further, the trans- 
Table 1a. HPV transfected DLD-1 cells

\begin{tabular}{|c|c|c|}
\hline transfected HPV & clone number & copies/cell \\
\hline \multirow[t]{4}{*}{ HPV 6} & 6D1 & 425.0 \\
\hline & $6 \mathrm{D} 2$ & 425.0 \\
\hline & 6D3 & 425.0 \\
\hline & $6 \mathrm{D} 4$ & 42.5 \\
\hline \multirow[t]{4}{*}{ HPV 16} & 16D1 & 275.0 \\
\hline & $16 \mathrm{D} 2$ & 27.5 \\
\hline & 16D3 & 2.75 \\
\hline & $16 \mathrm{D} 4$ & 2.75 \\
\hline \multirow[t]{5}{*}{ HPV 18} & $18 \mathrm{nD} 1$ & 38.5 \\
\hline & $18 \mathrm{nD} 2$ & 38.5 \\
\hline & $18 \mathrm{nD} 3$ & 38.5 \\
\hline & $18 \mathrm{nD} 4$ & 3.85 \\
\hline & $18 \mathrm{nD} 5$ & 3.85 \\
\hline \multirow[t]{8}{*}{ HPV 18} & 18hD1 & 3850.0 \\
\hline & $18 \mathrm{hD} 2$ & 385.0 \\
\hline & $18 \mathrm{hD} 3$ & 38.5 \\
\hline & $18 \mathrm{hD} 4$ & 38.5 \\
\hline & $18 \mathrm{hD} 5$ & 3.85 \\
\hline & $18 \mathrm{hD} 6$ & 3.85 \\
\hline & $18 \mathrm{hD} 7$ & 3.85 \\
\hline & $18 \mathrm{hD} 8$ & 3.85 \\
\hline
\end{tabular}

Table 1b. HPV transfected PC-14 cells

\begin{tabular}{|c|c|c|}
\hline transfected HPV & clone number & copies/cell \\
\hline \multirow[t]{3}{*}{ HPV 6} & $6 \mathrm{P} 1$ & 42.5 \\
\hline & $6 \mathrm{P} 2$ & 4.25 \\
\hline & $6 \mathrm{P} 3$ & 4.25 \\
\hline \multirow[t]{15}{*}{ HPV 16} & $16 \mathrm{P} 1$ & 275.0 \\
\hline & $16 \mathrm{P} 2$ & 27.5 \\
\hline & $16 \mathrm{P} 3$ & 27.5 \\
\hline & $16 \mathrm{P} 4$ & 27.5 \\
\hline & $16 \mathrm{P} 5$ & 27.5 \\
\hline & $16 \mathrm{P} 6$ & 27.5 \\
\hline & $16 \mathrm{P} 7$ & 2.75 \\
\hline & $16 \mathrm{P} 8$ & 2.75 \\
\hline & $16 \mathrm{P9}$ & 2.75 \\
\hline & $16 \mathrm{P} 10$ & 2.75 \\
\hline & 16P11 & 2.75 \\
\hline & $16 \mathrm{P} 12$ & 2.75 \\
\hline & $16 \mathrm{P} 13$ & 2.75 \\
\hline & $16 \mathrm{P} 14$ & 2.75 \\
\hline & $16 \mathrm{P} 15$ & 2.75 \\
\hline \multirow[t]{9}{*}{ HPV 18} & $18 \mathrm{nP} 1$ & 38.5 \\
\hline & $18 \mathrm{nP} 2$ & 38.5 \\
\hline & $18 \mathrm{nP} 3$ & 38.5 \\
\hline & $18 \mathrm{nP} 4$ & 38.5 \\
\hline & $18 \mathrm{nP} 5$ & 38.5 \\
\hline & $18 \mathrm{nP} 6$ & 3.85 \\
\hline & $18 \mathrm{nP7}$ & 3.85 \\
\hline & $18 \mathrm{nP} 8$ & 3.85 \\
\hline & $18 \mathrm{nP9}$ & 3.85 \\
\hline HPV 18 & $18 \mathrm{hP} 1$ & 38.5 \\
\hline
\end{tabular}

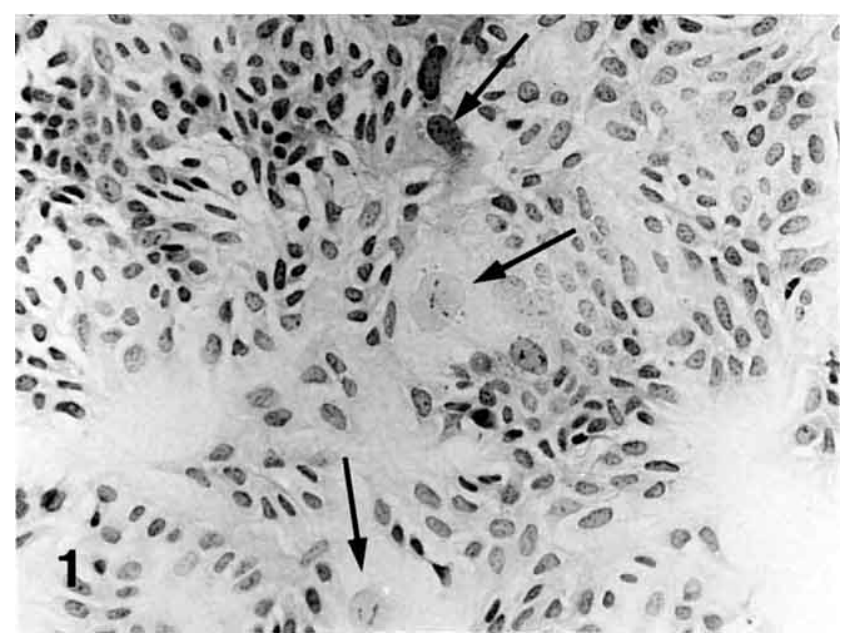

Fig. 1. Cultured adenocarcinoma DLD-1 cells transfected with HPV 16 (16D1). The expression of E2 and E6-E7 fusion genes is demonstrated by RT-PCR in these cells. Enlarged cells (arrows) with abundant cytoplasm are noted. $\times 150$.

glutaminase I [6] and involucrin mRNAs were also detected in these cells by use of RT-PCR $[13,16]$. The growth of HPV transfected cells was reduced, and the G0-G1 cell population increased.

\section{Expression of transfected HPV genome}

The expression of transfected HPV genome is variable $[9,13,18,22]$ among the cell lines as shown in Fig. 3. The tumor cells expressing the E2 and E6-E7 fusion gene (Fig. 3a) clearly showed phenotype change from adenocarcinoma to squamous cell carcinoma/or squamous metaplasia. The L1 and L2 regions of the HPV were not transcribed in the HPV transfected cells.

For the phenotype change/squamous metaplasia, the expression of E2 and E6-E7 fusion gene seemed to be essential. Next the effect of these genes was examined. In this case, E2, E6 and E7 were obtained from HPV in plasmid pBR322 separately, and ligated into pcDNA3.1 vector (Invitrogen, Life Technologies) at EcoRV site. Each gene was strongly expressed by the CMV (cytomegalovirus) promoter function contained in the vector. After transfection of the genes the cells became larger with abundant cytoplasm. But this effect was more apparent in the cells transfected with combined E2 and E6-E7 fusion genes [13]. The effect of single gene transfections were very similar, showing expression of involucrin. However, HMK expression was weak in the cells with single gene transfections.

\section{Expression of Molecular Markers in Squamous Cells}

\section{Expression of molecular markers in human adenocarcinoma cases}

We have reported many cases of adenosquamous carcinomas of the lung and endometrium in Okinawa. HPV was 

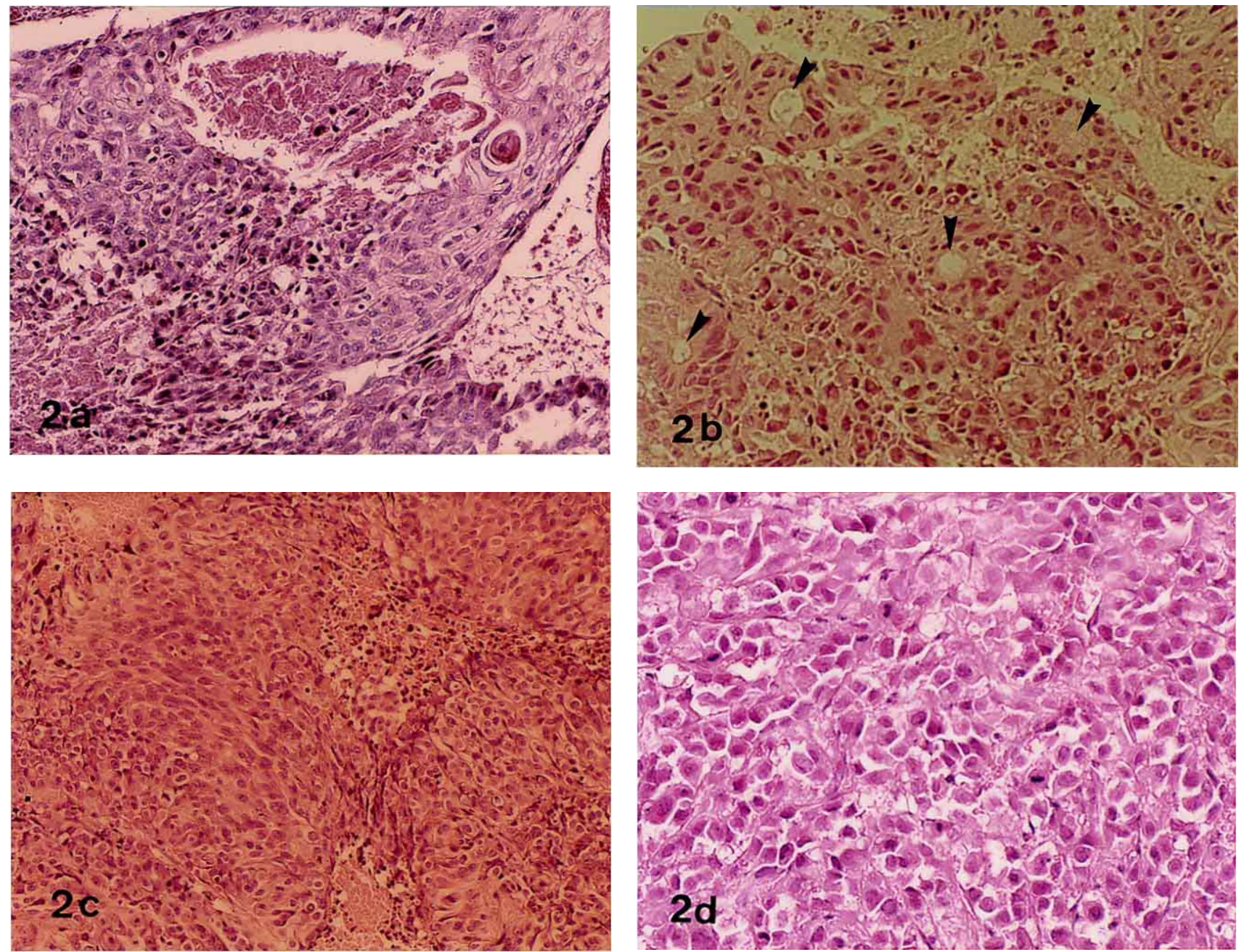

Fig. 2. a: Moderately differentiated squamous cell carcinoma which is formed by injection of HPV 16 transfected cells (16D1) into SCID mice. The expression of E2 and E6-E7 fusion genes is detected in this tumor. H\&E staining. $\times 150$. b: Control DLD-1 cells without HPV transfection. Adenocarcinoma (DLD-1 cells injected into SCID mice) characterizes by tubular structures (arrowheads). H\&E staining. $\times 150$. c: HPV 16 transfected PC-14 cells (16P1 cells). Squamous metaplasia (phenotype change from adenocarcinoma to squamous cell carcinoma) is demonstrated, but basal cell-like cells are observed. The HPV transfected cells (16P1) are injected into the backs of SCID mice. H\&E staining. $\times 150$. d: Control PC-14 cells without HPV transfection. Poorly differentiated adenocarcinoma is noted. H\&E staining. $\times 150$.

detected in the squamous cell carcinoma components and in neighboring enlarged adenocarcinoma cells in the case of adenosquamous carcinoma as reported previously [31]. HMK and involucrin were demonstrated immunohistochemically in the same areas (Fig. 4). These are thought to indicate the transition from adenocarcinoma to squamous cell carcinoma, in other words, to indicate the phenotype change/squamous metaplasia caused by HPV infection.

\section{Expression of molecular markers in HPV transfected cancer cells}

Recently, Hadaschik et al. [10] reported that HPV E2 protein interacted with $\mathrm{C} / \mathrm{EBP}$ (CCAAT/enhancer binding protein), and enhanced keratinocyte differentiation.

On the other hand, Tinsley et al. [29] have previously reported that HPV 1 transgenic mice expressing mainly E4 showed hyperplasia and hyperkeratosis of the skin. They also reported abnormal differentiation of the skin and the absence of keratin 10 expression.

In our current study $[13,16]$ the effects of HPV transfection into cultured adenocarcinoma cells were examined. In the HPV transfected cultured adenocarcinoma cells which were expressing both the E2 and E6-E7 fusion genes, HMK and involucrin were strongly demonstrated, and caused the change of phenotype to squamous cell carcinoma [13]. Further, involucrin and transglutaminase I mRNAs [6] were also detected strongly by use of the RT-PCR method. Histologically, HPV transfected cells showed the phenotype change from adenocarcinoma to squamous cell carcinoma with intercellular bridges. Many desmosomes were also clearly demonstrated by means of electron microscopy. 

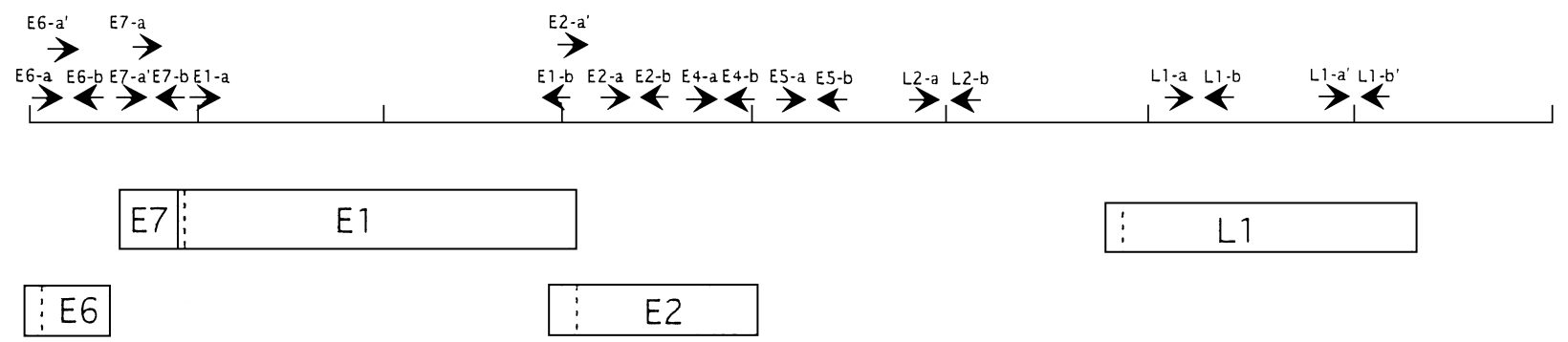

E4

\begin{tabular}{lll}
\hline$E 5$ & $L 2$ \\
\hdashline
\end{tabular}

a.

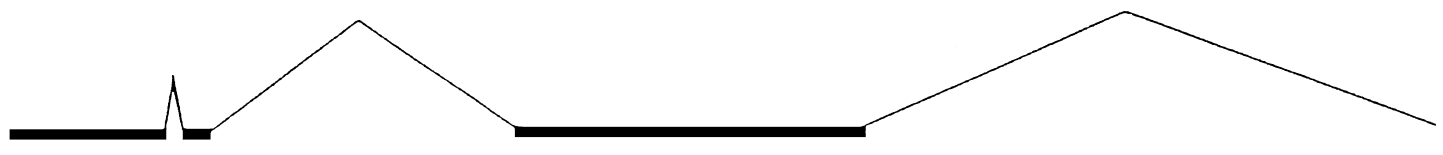

b.

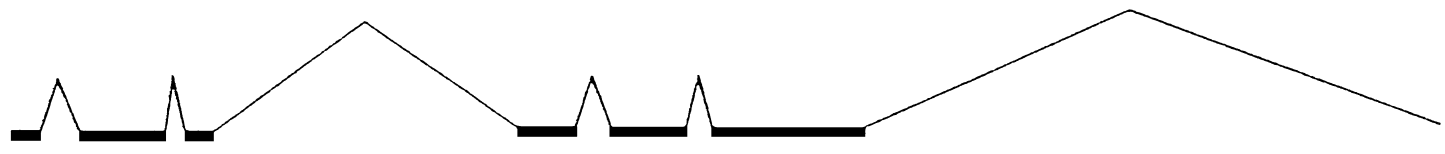

C.

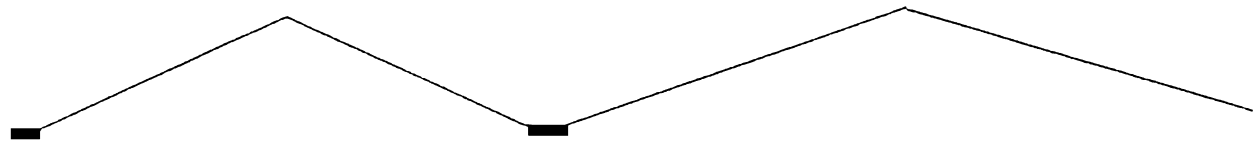

d.

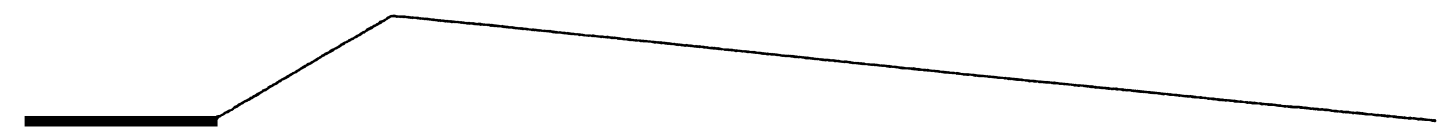

Fig. 3. Various transcripts of transfected HPV 16. The genome organization of HPV and position of the primers (arrows) used for PCR are shown at the top. The slanted lines represent intervening sequences removed by splicing. a, $\mathbf{b}, \mathbf{c}$ and $\mathbf{d}$ are the transcription patterns of the HPV in DLD-1. a: Phenotype change is apparent (16D1). b and $\mathbf{d}$ : Also show squamous cell differentiation. c: Squamous differentiation is not seen. In the case of PC-14 cells, similar transcript of HPV are demonstrated. However, in the case of HPV transfected PC-14, basal cell differentiation is frequently observed. It is thought that the poorly differentiated characteristics of the PC-14 cells influence the differentiation of the metaplastic cells.

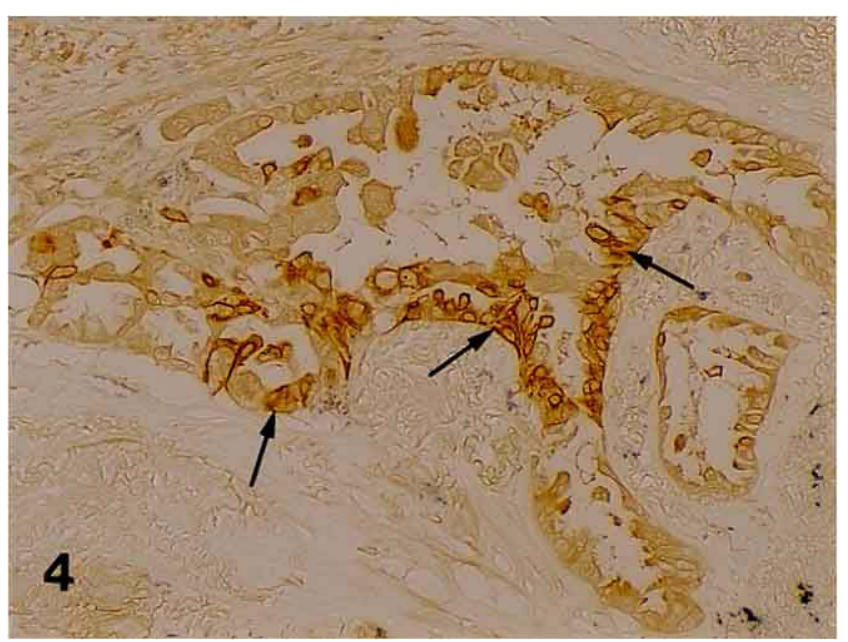

Fig. 4. Immunohistochemical demonstration of involucrin in adenosquamous carcinoma of the lung in Okinawa. Involucrin (arrows) is strongly demonstrated in adenocarcinoma cells neighboring the squamous cell components in adenosquamous carcinoma of the lung. $\times 150$. The specimen was obtained from a 51-year-old male patient. The tumor was located at right S3 lobe. 


\section{Changes in the Cell Cycle Associated Molecules}

\section{Expression of the cell cycle associated molecules by HPV transfection}

The expression of the cell cycle association molecules, cdk2, cdk4, cdk6, cyclin D1, cyclin D2, cyclin D3, cyclin E, p16 $\alpha$ and p16 $\beta$ was examined using the RT-PCR method $[13,16]$. Before and after HPV transfection into the cultured adenocarcinoma cells, the level of expression of some of these molecules changed slightly. In particular, the expression of cdk2 and cyclin D3 decreased, whereas cdk4 and p16 $\alpha$ and p16 $\beta$ were not detected at all by RT-PCR in the cells either before or after HPV transfection. The growth of the HPV transfected cells was reduced, probably influenced by the decrease in cdk2 and cyclin D3 levels. Although there was reduced growth of HPV transfected cells, G0-G1 cell numbers increased after HPV transfection.

\section{p53 and Rb genes and cell cycle}

Up to now it has been reported that the HPV E6 and E7 proteins interact with $\mathrm{p} 53$ and $\mathrm{Rb}$ proteins which regulate the cell cycle and inhibit the G0-G1 and G1-S phase transitions [5, 7, 18, 22, 30]. Pei [18] reported that retroviruses expressing HPV-E6/E7 genes infected on cultured human foreskin keratinocytes increase the cyclin A and B and cdc2 , and decrease the p53 protein and involucrin. Further, in human squamous cell carcinomas and also adenosquamous carcinomas of the lung, and endometrial adenosquamous carcinomas, the mutation of p53 gene have been reported. Inactivation of p53 and Rb associated with HPV infection promotes cell proliferation by relieving G1 growth arrest. However, the p53 gene mutation in non-small cell lung cancer samples has been reported to be about $50 \%$. In Okinawa $40 \%$ of HPV-infected and $43.8 \%$ of HPV-non-infected squamous cell carcinoma of the lung showed a p53 gene mutation. No significant correlation was found between p53 gene mutation and squamous differentiation. The change of $\mathrm{Rb}$ gene is also not correlated the squamous differentiation. Separately, Polyak et al. [20] reported that expression of p53 in cancer cells could result in either growth arrest or apoptosis. They examined the effect of exogenous wild-type p53 over-expression on the proliferation of p53 gene mutated and inactivated cultured cancer cells (DLD-1 cells, etc.). The wild-type p53 in adenovirus vector infection resulted in apoptosis and growth arrest mediated by $\mathrm{p} 21$ expression in cancer cells [20,34]. In our experiments, the number of apoptotic cells increased after HPV transfection with expression of E2 and E6-E7 genes, although p53 gene of the cultured adenocarcinoma cells, DLD-1 and PC-14 had mutated and been inactivated [16, 20, 34]. Therefore induced apoptosis was considered to occur through a non-p53 dependent pathway. The transcription of p14 ${ }^{\mathrm{ARF}}$ and MDM2 (murine double minute 2) should be examined in our experiment. Stott et al. (1998) [25] reported that p14 ${ }^{\mathrm{ARF}}$ acted by binding directly to MDM2, resulting in the stabilization of MDM2. p14 ${ }^{\mathrm{ARF}}$ induced cell cycle arrest could be abrogated by the expression of HPV E6 protein. Although the E6-p53 interaction has been emphasized, other functions of HPV E6, for example transcriptional transactivating activity should be considered [33]. Further, Rb/E2F interaction also regulated the cell cycle. The effects of HPV transfection on Rb gene in cell cycle regulation was obscure, although the level of cdk2 decreased slightly in HPV transfected DLD-1 cells [13]. Separately a direct interaction between HPV E7 and cyclin A has also been reported [33]. Cyclin A-cdk2-E2F and 107 $\mathrm{kD}$ protein complex is found at $\mathrm{S}$ phase. In our experiment, decrease of cdk2 might influence the formation of such a complex. Sousa et al. [22] have described how it seems clear that transcription of viral genes occurs through the interaction of many elements, both viral and cellular, which determine in part the species-, tissue-, and cell-specificities of the viruses $[9,23]$.

\section{Expression of Apoptosis Association Molecules}

\section{Apoptosis of mediated by HPV transfection}

After HPV transfection, the apoptotic cells increased in number. Using the terminal deoxynucleotidyl transferase mediated dUTP biotin nick and labelling method (TUNEL) [14] many apoptotic cells were demonstrated in all HPV transfection cases, whether of type 6,16 or 18 (Fig. 5). The transcription levels of caspase 8, DNase $\gamma$ and AIF (apoptosis inducing factor) [27, 28] apparently increased in HPV transfected cells, although the levels of caspase 3 and 9, Fas, Fas L, bax and bcl-2 mRNA did not change after HPV transfection. Levels of caspase 3 and 9 were lower than that of caspase 8. However, in one HPV 16 transfected clone which was expressing the E2 and E6-E7 fusion genes, the transcription of DNase $\gamma$ was strongly demonstrated, although caspase 8 mRNA was not detected [13]. The expression of

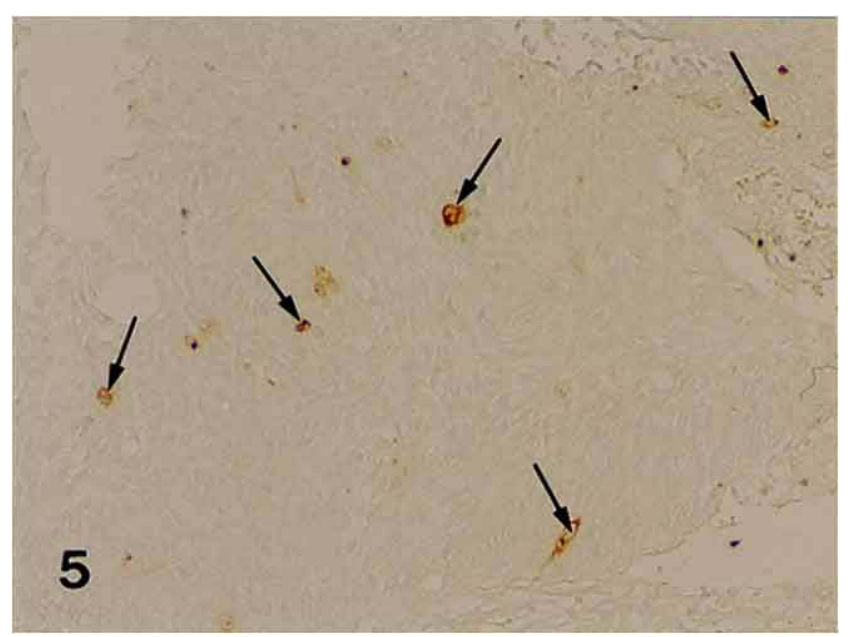

Fig. 5. Apoptotic cells in the HPV 16 transfected tumor (16D1) in SCID mice. Moderately differentiated squamous cell carcinoma which is expressing E2 and E6-E7 fusion genes. Arrows indicate apoptotic cells. TUNEL method. $\times 150$. 
caspase 8 was variable among the cell clones. Fas ligand was not expressed, and Fas mRNA level was low in all HPV transfected cell clones. The mRNA levels of bcl-2 and bax did not vary among the different cell clones. It was considered that the strong expression of DNase $\gamma$ might depend on a unique pathway, different to the caspase 3 and 9 associated route. The expression of DNase $\gamma$ was observed to be higher in the cells expressing E2 and E6-E7, and this seemed to be related to the phenotype change [13].

\section{p53 gene and apoptosis}

Waldman et al. [34] and Polyak et al. [20] described that expression of p53 induced $\mathrm{p} 21^{\mathrm{WAF} 1}$ expression, and that p21 mediated growth arrest that protects cells from apoptosis. Further, wild-type p53 transfection resulted in apoptosis in cultured p53 inactivated cancer cells, while inactivation of p53 gene promoted cell proliferation [20, 34]. In our experiment, DLD-1 and PC-14 cells, p53 gene mutated and inactivated cultured cancer cells [20,34] were used. HPV transfection induced the apoptosis and inhibition of cell growth in a non-p53 dependent fashion [13].

\section{Conclusion}

\section{Squamous differentiation and HPV transfection}

In this paper we have reported how the combined transcription of HPV E2 and E6-E7 fusion genes caused the phenotype change/squamous metaplasia from adenocarcinoma to squamous cell carcinoma. The transactivation of certain cellular genes was considered necessary to change the phenotype.

A reduced rate of cell growth was observed by the transfection of HPV. Changes of few cell cycle-associated molecules expression might also be induced by E2 gene transfection [13]. E2 protein interacted with C/EBP, and enhanced the involucrin expression and keratinocyte differentiation [10]. Apoptosis also occurred after the E6 and/or E7 transfection [21, 24]. In this study, we employed the cultured adenocarcinoma cells DLD- 1 and PC-14 which had the mutated p53 gene. p53 is known to function as a G1-checkpoint in the cell cycle, and its inactivation enhances cell growth [7, 22]. p53 in DLD-1 and PC-14 was in the inactivated state, and cell proliferation by relieving G1 growth arrest is considered to be promoted [20, 34]. However, in our experiment, apoptosis and inhibition of cell growth non-p53/p21 dependent route [20,34] induced by HPV transfection might influence the phenotype change. The expression of the molecular markers of squamous cells is more important. The factors, e.g. trans-activation proteins for these genes, are present in this study on HPV E2 and E6-E7 fusion genes. It is considered that such in situ cellular homologous factors for these genes are dominant factors for the phenotype change/squamous metaplasia. Further studies are also needed to clarify other abnormal stimuli in addition to HPV and smoking which cause the "squamous metaplasia". Although squamous differentiation was rare in intestinal and gastric carcinomas, colonic carci- noma cells (DLD-1) showed clear squamous differentiation. In the present study, it was considered that squamous differentiation was induced in a HPV non-tissue type dependent fashion.

\section{Squamous differentiation and other factors}

It has been reported that smoking causes squamous metaplasia of the bronchial epithelium [19], and that the squamous metaplasia induced by smoking is reversible. Further, chronic endometritis, hypovitaminosis A, irradiation and chronic irritative processes such as intrauterine devices and proplapse have been considered to be pathogenic factors for squamous metaplasia of the endometrium [37]. However, what molecular expression and biological events occurred in the bronchial and endometrial epithelial cells have not been studied. Further, the loss of cell-cell adhesion molecules, eg. cadherin, and $\beta$-catenin, etc. generate dedifferentiation of cancer cells [9]. The effect of cell to cell adhesion molecules on squamous differentiation should also be studied.

In conclusion, transfection of HPV induced the phenotype change from adenocarcinoma to squamous cell carcinoma. However, the most essential factor in the phenotype change/squamous differentiation still remains obscure.

\section{References}

1. Bloor, B. K., Lan, S., Shirlaw, P. J. M. and Morgan, P. R. (1998) Gene expression of differentiation-specific keratins (4/13 and $1 / 10$ ) in normal buccal mucosa. Lab. Invest. 78; 787-795.

2. Bouvard, V., Storey, A., Pim, D. and Banks, L. (1994) Characterization of the human papillomavirus E2 protein: evidence of trans-activation and trans-repression in cervical keratinocytes. EMBO J. 13; 5451-5459.

3. Chen, C. and Okayama, H. (1987) High-efficiency transformation of mammalian cells by plasmid DNA. Mol. Cell. Biol. 7; 27452752.

4. Dexter, D. L., Barbosa, J. A. and Calabresi, P. (1979) N, N-dimethylformamide-induced alteration of cell culture characteristics and loss of tumorigenicity in cultured human colon carcinoma cells. Cancer Res. 39; 1020-1025.

5. Dowhanick, J. J., McBride, A. A. and Howley, P. M. (1995) Suppression of cellular proliferation by the papillomavirus E2 protein. J. Virol. 69; 7791-7799.

6. Duvic, M., Nelson, D. C., Annarella, M., Cho, M., EsgleyesRibot, T., Remenyik, E., Ulmer, R., Rapini, R. P., Sacks, P. G., Clayman, G. L., Davies, P. J. A. and Thacher, S. (1994) Keratinocyte transglutaminase expression varies in squamous cell carcinomas. J. Invest. Dermatol. 102; 462-469.

7. Frattini, M. G., Hurst, S. D., Lim, H. B., Swaminathan, S. and Laimins, L. A. (1997) Abrogation of a mitotic checkpoint by E2 proteins from oncogenic human papillomaviruses correlates with increased turnover of the $\mathrm{p} 53$ tumor suppressor protein. EMBO J. 16 ; 318-331.

8. Frixen, U. H., Behrens, J., Sachs, M., Eberle, G., Voss, B., Warda, A., Lochner, D. and Birchmeier, W. (1991) E-cadherinmediated cell-cell adhesion prevents invasiveness of human carcinoma cells. J. Cell Biol. 113; 173-185.

9. Fuchs, P. G. and Pfister, H. (1994) Transcription of papillomavirus genomes. Intervirology 37; 159-167.

10. Hadaschik, D., Hinterkense, K., Oldak, M., Pfister, H. J. and Smola-Hess, S. (2003) The papillomavirus E2 protein binds to 
synergizes with C/EBP factors involved in keratinocyte differentiation. J. Virol. 77; 5253-5265.

11. Hirayasu, T., Iwamasa, T., Kamada, Y., Koyanagi, Y., Usuda, H. and Genka, K. (1996) Human papillomavirus DNA in squamous cell carcinoma of the lung. J. Clin. Pathol. 49; 810-817.

12. Hwang, E.-S., Riese, D. J. H., Settleman, J., Nilson, L. A., Honig, J., Flynn, S. and DiMaio, D. (1993) Inhibition of cervical carcinoma cell line proliferation by the introduction of a bovine papillomavirus regulatory gene. J. Virol. 67; 3720-3729.

13. Kinjo, T., Kamiyama, K., Chinen, K., Iwamasa, T., Kurihara, K. and Hamada, T. (2003) Squamous metaplasia induced by transfection of human papillomavirus DNA into cultured adenocarcinoma cells. Mol. Pathol. 56; 97-108.

14. Matsumoto, N., Suzuki, K., Katoh, R., Hara, Y. and Kawai, A. (1993) Evaluation of the in situ nick translation, as a method to detect apoptosis. Acta Histochem. Cytochem. 26; 490.

15. Moll, R., Franke, W. W., Schiller, D. L., Geiger, B. and Krepler, R. (1982) The catalog of human cytokeratins: patterns of expression in normal epithelia, tumors and culture cells. Cell 31; 11-24.

16. Nakazato, I., Hirayasu, T., Kamada, Y., Tsuhako, K. and Iwamasa, T. (1997) Carcinoma of the lung in Okinawa, Japan: with special reference to squamous cell carcinoma and squamous metaplasia. Pathol. Int. 47; 659-672.

17. Parsons, H. A. (2000) Disorders of growth, differentiation and morphogenesis. In "General and Systemic Pathology", 3rd ed., ed. by L. C. E. Underwood, Churchill Livingstone, Edinburgh, pp. 73-99.

18. Pei, X. F. (1996) The human papillomavirus E6/E7 genes induce discordant changes in the expression of cell growth regulatory proteins. Carcinogenesis 17; 1395-1401.

19. Peters, E. J., Morice, R., Benner, S. E., Lippman, S., Lukeman, J., Lee, J. S., Ro, J. Y. and Hong, W. K. (1993) Squamous metaplasia of the bronchial mucosa and its relationship to smoking. Chest $103 ; 1429-1432$

20. Polyak, K., Waldman, T., He, T-C., Kinzler, K. W. and Vogeltsein, B. (1996) Genetic determinations of p53-induced apoptosis and growth arrest. Genes Dev. 10; 1945-1952.

21. Sanchez-Perez, A. M., Soriano, S., Clarke, A. R. and Gaston, K. (1997) Disruption of the human papillomavirus type 16 E2 gene protects cervical carcinoma cells from E2F-induced apoptosis. J. Gen. Virol. 78; 3009-3018.

22. Sousa, R., Dostatni, N. and Yaniv, M. (1990) Control of papillomavirus gene expression. Biochim. Biophys. Acta 1032; 19-37.

23. Stoppler, H., Stoppler, M. C. and Schlegel, R. (1994) Transforming proteins of the papillomaviruses. Intervirology 37; 168-179.

24. Stoppler, H., Stoppler, M. C., Johnson, E., Simbulan-Rosenthal, C. M., Smulson, M. E., Iyer, S., Rosenthal, D. S. and Schlegel, R. (1998) The E7 protein of human papillomavirus type 16 sensitizes primary human keratinocytes to apoptosis. Oncogene 17; 1207-1214.

25. Stott, F. J., Bates, S., James, M. C., McConnell, B. B., Starborg,
M., Brookes, S., Palmero, I., Ryan, K., Hara, E., Vousden, K. H. and Peters, G. (1998) The alternative product from the human CDKN2A locus, p14 ${ }^{\mathrm{ARF}}$, participates in a regulatory feedback loop with p53 and MDM2. EMBO J. 17; 5001-5014.

26. Sun, Q., Tsutsumi, K., Kelleher, M. B., Pater, A. and Pater, M. M. (1992) Squamous metaplasia of normal and carcinoma in situ of HPV 16-immortalized human endocervical cells. Cancer Res. 52; 4254-4260.

27. Susin, S. A., Zamzami, N., Castedo, M., Hirsch, T., Marchetti, P., Macho, A., Dangas, E., Geuskens, M. and Kroemer, G. (1996) Bcl-2 inhibits the mitochondrial release of an apoptogenic protease. J. Exp. Med. 184; 1331-1341.

28. Susin, S. A., Lorenzo, H. K., Zamzami, N., Marzo, I., Brenner, C., Larochette, N., Prevost, M.-C., Alzari, P. M. and Kroemer, G. (1999) Mitochondrial release of caspase-2 and -9 during the apoptotic process. J. Exp. Med. 189; 381-394.

29. Tinsley, J. M., Fisher, C. S. and Searle, P. E. (1992) Abnormalities of epidermal differentiation associated with expression of the human papillomavirus type 1 early region in transgenic mice. J. Gen. Virol. 73; 1251-1260.

30. Tommasino, M. and Crawford, L. (1995) Human papillomavirus E6 and E7: proteins which deregulate the cell cycle. Bioessays $17 ; 509-518$

31. Tsuhako, K., Nakazato, I., Hirayasu, T., Sunakawa, H. and Iwamasa, T. (1998) Human papillomavirus DNA in adenosquamous carcinoma of the lung. J. Clin. Pathol. 51; 741-749.

32. Tsukasaki, S., Miyazaki, M., Koji, T., Abe, K., Furuse, A., Shin, M., Suzuki, D., Harada, T., Ozono, Y., Sakai, H. and Kohno, S. (2000) Semi-quantitative non-radioactive in situ hybridization and its clinical application. Acta Histochem. Cytochem. 31; 3947.

33. Vousden, K. H. (1994) Cell transformation by human papillomaviruses. In "Viruses and Cancer. Fifty-first Symposium of the Society for General Microbiology held at the University of Cambridge, March 1994," ed. by A. Minson, J. Neil and M. McGrae, Cambridge University Press, Cambridge, pp. 27-46.

34. Waldman, T., Kinzler, K. W. and Vogelstein, B. (1995) p21 is necessary for the p53-mediated G1 arrest in human cancer cells. Cancer Res. 55; 5187-5190.

35. Yaffe, M. B., Murthy, S. and Eckert, R. J. (1993) Evidence that involucrin is a covalently linked constituent of highly purified cultured keratinocyte cornified envelopes. J. Invest. Dermatol. $100 ; 3-9$.

36. Yeldandi, A., Kaugman, D. G. and Reddy, J. K. (1990) Cell injury and cellular adaptations. In "Anderson's Pathology," 10th ed., ed. by I. Damjanov and J. Linder, Mosby Year Books, St Louis, pp. 357-386.

37. Zidi, Y. S. H., Bouraoui, S., Atallah, K., Kchir, N. and Haouet, S. (2003) Primary in situ squamous cell carcinoma of the endometrium, with extensive squamous metaplasia and dysplasia. Gynecol. Oncol. 88; 444-446. 